\title{
CAPítTLLO 6
}

\section{UMA PRÁTICA DE ESCRITA OU A ESCRITA COMO PRÁTICA: A RELAÇÃO CAPS IJ E ESCOLA EM FOCO}

Renata Penalva

Em minha dissertação de mestrado, decidi escrever sobre a experiência que eu estava tendo à época enquanto trabalhadora de um Centro de Atenção Psicossocial Infanto-Juvenil (Caps-IJ). Busquei o mundo da pesquisa porque queria trabalhar as perguntas que vinham da prática. A prática, claro, trazia contradições. E a maneira como eu escrevia podia me guiar ou me deixar perdida na pesquisa em relação a essas contradições. Uma delas: nós, trabalhadoras ${ }^{23} \mathrm{da}$ saúde mental, vivíamos quase diariamente a situação em que instituições de fora do fazer clínico nos pediam informações sobre o diagnóstico psiquiátrico de uma criança ou um adolescente, bem como uma intervenção rápida e localizada para problemas complexos.

Incomodava-nos ver que um diagnóstico (por exemplo: deficiência intelectual) era comumente usado apenas para justificar insuficiências (por exemplo: uma criança não aprender os sons das letras em determinado tempo e não haver suportes

\footnotetext{
23 O texto trata da articulação de uma escrita individual e acadêmica com um trabalho coletivo em um serviço de saúde. O sujeito no texto alternará entre a primeira pessoa do singular e a primeira pessoa do plural conforme esses contextos forem abordados. A primeira pessoa do plural se dará no feminino, uma vez que a maioria das pessoas que trabalham nos serviços mencionados são mulheres.
} 
suficientes para auxiliá-la). Insuficiências essas que nem sempre diziam respeito somente a uma criança ou um adolescente específico. Esse uso do diagnóstico frequentemente dificultava que o entorno fosse repensado para dar conta do que era sentido como problema. No entanto, negar um relatório com o código do diagnóstico, negar o pedido em si tampouco operava as mudanças que queríamos ver. Os códigos da saúde sobrecodificam outras áreas de atuação e dão direitos importantes, como o acesso a transporte e a auxílios, ${ }^{24}$ e facilitam receber os apoios educacionais na perspectiva da educação inclusiva. ${ }^{25} \mathrm{E}$ tais direitos - cujo acesso é facilitado pelo diagnóstico clínico - possuem, por sua vez, importância considerável enquanto potenciais suportes no cuidado da criança ou do adolescente sobre quem se pede diagnóstico e solução rápida.

Quando a psiquiatra do Caps negava que se medicasse e se fizesse ressonância magnética em uma adolescente que "vinha revoltada já fazia três semanas" depois de a terem separado dos irmãos, a origem do pedido não era repensada, mas se organizava de outra maneira: os cuidadores buscavam outro serviço. Por outro lado, se fosse dado um nome psiquiátrico à revolta e uma medicação fosse prescrita, isso não era suficiente para atuar no que causava sofrimento na adolescente, nem sequer esclarecia o que lhe passava, pois não é disso que um diagnóstico clínico trata. Dar ou negar um diagnóstico não atuava nas insuficiências que pediam por ele. O trabalho do Caps - o trabalho de cuidar de quem está em sofrimento e de não deixar que esse sofrimento defina todas as relações possíveis com o mundo - incitava-nos a questionar o efeito que as letras em um relatório produziam na pessoa sobre quem se escrevia. No entanto, como já dito, os códigos da saúde sobrecodificam outros códigos da vida e podem garantir importantes elementos, de direitos a alívio de culpa. Como transcender ao funcionamento que pede um nome e uma resolução simples para problemas complexos sem também diminuir o fenômeno com uma negação simples? Como inventar novos modos de agir nas insuficiências?

24 Como o Benefício de Prestação Continuada (BPC).

25 Muito embora os instrumentos da educação prescindam de um diagnóstico clínico para atuar (Angelucci, 2014). Vale lembrar que a Política Nacional de Educação Especial na Perspectiva da Educação Inclusiva sofreu grandes ataques entre as diferentes versões deste texto. Primeiro, com o decreto 10.502/20, que regredia as políticas educacionais inclusivas ao corroborar com a segregação de pessoas com deficiência da educação regular. Esse decreto foi suspenso pelo Superior Tribunal Federal. Segundo, por aprovação na Câmara de um ponto na regulamentação do FUNDEB que liberaria fundos públicos para instituições educacionais particulares, incluindo para as de educação especial, o que desviaria investimento do setor público para o privado. Essa ação foi retirada no Senado. Ambas as ações foram revertidas graças à mobilização de pessoas com deficiências, familiares, organizações da sociedade civil. 
Busquei a pesquisa para que ela ajudasse a resolver as contradições que enfrentava no cotidiano... Mas a pesquisa não poderia se dar fora do campo, pois era a prática em si em um serviço de saúde que impunha a invenção cotidiana e imediata de soluções e problematizações. A pesquisa ajudava a levar ao Caps perguntas não pensadas e questionamentos dos paradigmas que enfrentávamos no dia a dia. A pesquisa informava a prática, que modificava a pesquisa. A esse procedimento, de conhecer o campo ao mesmo tempo em que se atua nele, Adriana Marcondes, orientadora deste trabalho, ensinou que se nomeava pesquisa-intervenção (Aguiar \& Rocha, 2007). Fazer uma pesquisa-intervenção teve implicações na escrita. Não era possível fazer uma escrita teórica e distante das situações do campo, como fora imaginada inicialmente. Os achados e as discussões dos autores lidos, as anotações e os fichamentos não poderiam apenas se somar em uma escrita distante do diálogo com as situações cotidianas, uma vez que estavam totalmente imbricados.

Entretanto, as seguintes perguntas seguiam me acompanhando a cada parágrafo em primeira pessoa: qual a finalidade de uma escrita que traz a experiência do pesquisador? O que se conquista com isso? O receio de cair em uma escrita ensimesmada, sem ressonância com o coletivo, era constante. Escrever sobre o trabalho com a infância e a juventude carrega ainda o receio de falar por eles, e não a partir da relação com eles. A infância e a juventude há tempos têm suas imagens construídas por discursos externos.

O início de Capitães da areia, de Jorge Amado, livro que tem como protagonistas crianças e adolescentes, serve-nos de ilustração para essa situação. Na apresentação dos protagonistas, há uma sequência de notícias de jornais em que adultos falam sobre os capitães da areia. A primeira manchete diz "Creanças Ladronas - as aventuras sinistras dos 'capitães da areia' - a cidade infestada por creanças que vivem do furto - urge uma providência do juiz de menores e do chefe de polícia - hontem houve mais um assalto" (Amado, 1937, p. 20). As próximas páginas trazem cartas ao jornal de diferentes adultos-instituições - o secretário de polícia, o doutor juiz de menores, uma mãe costureira, o padre, o diretor do reformatório - apresentando questões relacionadas às crianças. Um após o outro, esses adultos-instituições vão convocando um próximo e repassando a responsabilidade que lhes fora endereçada.

Por essas cartas, conseguimos obter alguns relances sobre o que são os meninos pelos vãos dos discursos que os contornam. Mas só depois saberemos dos meninos. O chefe de polícia os chama de "delinquentes". O juiz os denomina como "menores, delinquentes ou abandonados" e adiciona que os encaminha ao 
Reformatório de Menores, mas que de lá muitos fogem. A carta da mãe conta que o juiz "mandava os pobres" para o Reformatório, de onde ela tirou seu filho, e recomendava que os jornalistas fossem ao reformatório escondidos para ver o que lá de fato se passava com "os filhos dos pobres que teem a desgraça de cair nas mãos daqueles guardas sem alma”. Acrescenta ainda que "o diretor de lá vive caindo de bêbado e gosta de ver o chicote cantar nas costas dos filhos dos pobres" (p. 27). O padre confirma o conteúdo da carta da mãe e relata não conseguir levar às crianças o consolo da religião, porque as encontra no reformatório pouco dispostas, "devido naturalmente ao ódio que estão acumulando naqueles jovens corações tão dignos de piedade". A última carta é a do diretor do reformatório, que descredita o conteúdo da carta da mãe, chama-a de "mulherzinha" e de "uma das muitas que aqui veem". Afirma também que mulheres como ela deveriam agradecer por ele fazer de seus filhos "homens de bem", criticando a educação que elas dão aos filhos. Ainda se queixa da conduta do padre, que causa rebeldia no reformatório.

Eu relembrei essas cenas em uma reunião de rede, em que estávamos trabalhadoras da saúde, da educação e do serviço social - discutindo sobre como proceder com um menino que acabara de sair da Fundação Casa, estava cumprindo medida socioeducativa e havia sumido. As profissionais do serviço social e da escola pediam que o Caps saísse pelas ruas e o encontrasse. A médica do Caps dizia que era trabalho da Unidade Básica de Saúde (UBS), e a psicóloga da UBS dizia não encontrar mais a mãe do menino para saber dele, e que isso deveria ser trabalho do pessoal da medida socioeducativa. Depois que comentei que parecíamos com o começo de Capitães de areia nessa reunião, entendemos o que estávamos fazendo: cada uma acreditando piamente em sua proposta de ação como inteira e passando o problema à outra, contornando e nunca pensando no menino exatamente nem aceitando que a situação denunciava também os nossos limites. A reunião passou a girar em torno do que podíamos fazer, cada uma, juntas, somando nossos saberes e os furos entre eles: lembrar as últimas conversas com o menino, coordenar ações e, também, admitir o que não poderia ser feito.

Essa cena ajudou a criar mudanças na minha dissertação e a orientar a ética da escrita que este trabalho convocava: entendi que, para escrever sobre minha experiência, para que ela tenha relevância coletiva, para que ela não apague os adolescentes, as crianças nem os colegas de rede que também se dedicam a elas, a escrita deve, constantemente, sofrer edições que me limitem e localizem e que não reduzam o outro. Trata-se de atuar para além do que fazem essas cartas, que 
tentam explicar um fenômeno a partir do que se alcança ver, assim como atribuem os problemas a outra esfera distante da atuação própria.

Para isso, era necessário assumir as ações do Caps sobre infância e juventude: na criação de discursos sobre infância e juventude e na responsabilidade pelos efeitos que advinham dos múltiplos discursos. Entender o Caps não como $o$ lugar que melhor pode falar sobre as crianças que atende, mas como mais um nesse contorno. Atentas a isso, entendendo os limites e as potências de nossa atuação, abríamos espaço para compreendermos as crianças e os jovens pelos vãos e percebermos o que deles é reflexo de nossas atuações. Como conectar essa posição ética a uma escrita que fala da experiência de uma trabalhadora?

Explico os caminhos que encontrei para o como por meio de dois aspectos que serão aqui salientados: o primeiro trata do porquê escrever sobre isso, afinal, e o segundo trata da escrita como procedimento. Comecemos pelo porquê: como dito anteriormente, a pesquisa trazia novas maneiras de enxergarmos o problema que enfrentávamos no dia a dia, e aqui coloco a primeira pessoa do plural, porque a pesquisa fazia sentido quando compartilhada com alguém do cotidiano - trabalhador da rede, adolescente - e quando percebia na reação desse alguém a mesma sensação de Eureka que a pesquisa me trazia. Tanto o compartilhamento dos ensinamentos da pesquisa quanto as leituras em si tinham este fio em comum: a força de se descobrir entrelaçado com o que é coletivo e perceber, nas malhas de outros possíveis, perguntas e respostas não pensadas para os problemas que víamos no cotidiano. Fortalecia saber que aqueles problemas que enfrentávamos no dia a dia do serviço e na lida com o sofrimento humano faziam eco com a realidade de fora do serviço.

Esse entrelaçamento se assemelhava com o que um diagnóstico na clínica pode fazer. A nomeação de um sofrimento com uma palavra disponível no mundo cria existência. Mas, em vez de se tornar uma justificativa para a existência, o diagnóstico na clínica pode possibilitar uma recolocação da enunciação do sofrimento singular e indicar caminhos a se experimentar.

Éramos um serviço marcado pela insuficiência, não só de profissionais como de resultados. Nossos superiores salientavam e nomeavam bem o que não fazíamos corretamente, porém pouco sabíamos sobre como atuar nos nossos buracos. Fortalecia-nos ler e compreender que as coisas que se passavam naquele serviço não se davam por uma distorção excêntrica da realidade que corria fora e que havia formas de melhor endereçar o que enfrentávamos. As experiências dos outros e suas decorrências evidenciavam os mesmos funcionamentos: sucateamento, terceirização, problemas no gerenciamento de equipes de saúde. Ler 
um texto sobre o que aconteceu em algum outro Caps, como aquele problema foi pensado e como sua solução foi operacionalizada ajudava a conjeturar possíveis soluções. Mas isso só se dava quando a escrita localizava meu interlocutor. Se ele me informava as particularidades de seu território e de seu serviço, conseguíamos nos assemelhar e nos diferenciar. Dessa maneira, assim como os escritos dos outros davam forças para pensar nossa atuação no Caps, a escrita sobre o Caps só poderia servir ao coletivo se também localizasse e expusesse as variáveis em que os problemas se engendravam.

Retomemos a pergunta do como, agora mais delineada, para prosseguir ao procedimento: como cuidar para que as inflexões teóricas feitas a partir da ação no campo não fossem tomadas por produções extremamente subjetivistas que pouco servem ao coletivo? A pesquisa ganhava contorno quando a escrita se tornava procedimento. $\mathrm{O}$ diário de campo por si não conquistava, sozinho, novos entendimentos sobre um fenômeno. A pergunta da pesquisa, nesse momento de recompreensão do diário de campo, saía da posição de negar ou afirmar a necessidade de um diagnóstico e migrava para a atuação estratégica com a rede de cuidado, para agir nas insuficiências que pediam pelo diagnóstico ou pela resolução rápida. As primeiras escritas dos acontecimentos frescos no diário de campo não sabiam a que vinham, eram salpicadas de incômodos pessoais e poucas vezes moviam o pensamento... Contudo, tornaram-se material fundamental para o trabalho. A escrita, a reescrita e as discussões dessas situações vividas foram processo importante para expor os traços subjetivos na escrita e compreender melhor a complexidade em que os fenômenos vividos se materializavam.

O objetivo da pesquisa se delineou a partir da cena a seguir.

Primeira versão - "Graças a Deus eles faltam"

Duas técnicas de um Caps vão a uma escola discutir sobre Matheus, um adolescente que adorava cozinhar, estava aprendendo a escrever e estava cumprindo medida socioeducativa. Desde que saíra da Fundação Casa, Matheus ia a Caps. Não queria voltar para a escola. Demorou um mês para aceitar voltar a estudar. Só aceitou depois de uma discussão sobre direitos e saúde. Resolveu que seria advogado para defender pessoas como ele. Ao mesmo tempo que avisava as técnicas do Caps que se rematricularia na escola, dizia, quase em tom de aposta, que a escola não o quereria. A escola demorou um mês para aceitá-lo. A resposta positiva só aconteceu com a ameaça da profissional da medida socioeducativa, a psicóloga do Creas, de que faria um relatório para o juiz explicando que o município se recusava a dar educação para ele. No Caps, Matheus participava ativamente das atividades, propunha algumas e acolhia os novos jovens. Pouco 
tempo depois de entrar na escola, começou a faltar no Caps, dizia que não estava conseguindo resolver os conflitos na escola, que tinha raiva dos professores, que o culpavam por tudo. As técnicas foram conversar com os professores da escola. Estes as receberam e começaram uma grande lista de reclamações sobre Matheus. A moça da portaria as avisara que os professores iriam falar coisas ruins sobre ele, mas que ele era um bom menino. As técnicas, em resposta, começaram a contar todas as conquistas de Matheus no Caps, no esforço de contagiá-los com boas imagens de Matheus. Os professores responderam que eram dois Matheus, que ele as enganava. As técnicas notaram o uso do plural em algumas falas dos professores, ao se referir a "alunos que usam drogas". Perguntaram se havia outros como Matheus, que voltavam da medida socioeducativa, e como eles lidavam com esses outros. Uma professora responde: "Graças a Deus eles faltam". Todos os professores riem.

A cena no diário de campo ainda tinha outros detalhes sobre como os professores não entendiam Matheus. A pergunta da pesquisa nesse momento era resumida em: como fazer uma intersetorialidade que apoie os trabalhadores da educação em uma educação emancipatória? ${ }^{26}$ A questão, no entanto, era uma falsa questão. Pressupunha o Caps como lugar de saber sobre educação, pressupunha um papel que não era o convocado. Não olhava qual era o problema na cena. A orientadora da pesquisa lê e comenta: "há anos a saúde entra nas escolas ensinando o que fazer". Um giro: nós, trabalhadoras do Caps, querendo evitar que um discurso biomédico desse conta da totalidade do que era Matheus, caíamos e repetíamos a história que queríamos evitar, em que o discurso da saúde vai a outras áreas explicar a totalidade de entendimento sobre alguém! Se a equipe daquele Caps evitava processos de medicalização negando explicações gerais que pretendessem abarcar uma totalidade - uma explicação genérica para o uso de drogas -, desconsiderando a complexidade de fenômenos atravessados pelo social, ela, por outro lado, renovava os aspectos da medicalização: 1) expandindo o entendimento e as soluções cunhadas a partir da saúde para outras áreas da vida (Moysés \& Collares, 2013) e 2) referenciando uma proposta externa, ao ditar um "como fazer" alheio, em que se escapa à discussão ética entre pares capaz de buscar, por meio da corresponsabilização, estratégias de encontro (Conrad, 1975) com Matheus e a escola.

26 Como proposto por Saviani (2012), uma educação emancipatória é pensada a partir da compreensão dos determinantes sociais e deve se atentar às armadilhas: os mecanismos de adaptação da classe dominante fazendo-se de classe dominada. 
Não fomos ouvir as dificuldades que os professores viviam com Matheus, fomos disputar versões. A cena ganha novo título, "São dois Matheus", e se abre para as ações feitas pelo Caps na separação de Matheus em dois. Ganha nova análise. O nome Matheus foi escolhido nesse momento por ser plural no singular. Os elementos adicionados aqui estão em negrito:

\section{Segunda versão - "São dois Matheus"}

Duas técnicas de um Caps vão a uma escola discutir sobre Matheus, um adolescente que adorava cozinhar, estava aprendendo a escrever e estava cumprindo medida socioeducativa. Desde que saíra da Fundação Casa, Matheus ia a Caps. Não queria voltar para a escola. Demorou um mês para aceitar voltar a estudar. Só aceitou depois de uma discussão sobre direitos e saúde. Resolveu que seria advogado para defender pessoas como ele. Ao mesmo tempo que avisava às técnicas do Caps que se rematricularia na escola, dizia, quase em tom de aposta, que a escola não o quereria. A escola demorou um mês para aceitá-lo. Nem as trabalhadoras do Caps, nem as do Creas consideraram conversar com a escola para entender o que se passava lá nessa delonga e discutir a volta de Matheus. A resposta positiva só aconteceu com a ameaça da profissional da medida socioeducativa, a psicóloga do Creas, de que faria um relatório para o juiz explicando que o município se recusava a dar educação para ele. No Caps, Matheus participava ativamente das atividades, propunha algumas, acolhia os novos jovens. Pouco tempo depois de entrar na escola, começou a faltar no Caps, dizia que não estava conseguindo resolver os conflitos na escola, que tinha raiva dos professores, que o culpavam por tudo. As técnicas foram conversar com os professores da escola. Queriam que o Matheus que elas viam também pudesse aparecer na escola. Marcaram a reunião "para trocar", mas, entre si, supunham ter um melhor entendimento do que se passava com Matheus. Os professores as receberam e começaram a relatar todas as dificuldades que tinham com Matheus. A moça da portaria as avisara que os professores iriam falar dos incômodos com ele, mas que ele era um bom menino. A relação daquele corpo docente com o corpo de Matheus já tinha uma história de desgastes, dos quais havia sinais antes de a matrícula se efetivar. As técnicas, em resposta às falas dos professores, começaram a contar todas as conquistas de Matheus no Caps, no esforço de contagiá-los com boas imagens de Matheus. Dizer do sucesso do Caps com Matheus não melhorava a imagem de Matheus ali naquele momento, mas colocava na escola o lugar do fracasso e da impotência em lidar com Matheus. Colocar o Caps em foco não fazia os professores quererem ouvir Matheus $e$ se entenderem com ele. Os professores responderam que eram dois Matheus, 
que ele as enganava. As técnicas notaram o uso do plural em algumas falas dos professores, ao se referir a "alunos que usam drogas". Ouviam premissas que lhes davam a impressão de que eles nunca tinham tido a chance de um espaço para conversar sinceramente com esses jovens e ouvir sobre como o uso de drogas se encaixava na vida deles. Ao perceber esse plural quando falavam de Matheus, as técnicas perguntaram se havia outros como Matheus, que voltavam da medida socioeducativa, e como eles lidavam com esses outros. Uma professora responde: "Graças a deus eles faltam". Todos os professores riem. A reunião termina com as técnicas do Caps valorizando o fato de que Matheus ainda ia à escola e com a coordenadora pedindo para que elas retornassem, a fim de explicar mais sobre os efeitos das drogas.

Analisar uma cena anda junto com construí-la (Machado, 2016). O objetivo da pesquisa se redesenhou: não se tratava mais de resolver as insuficiências do outro a partir de nossas ações na rede - a pergunta sobre como apoiar uma educação emancipatória na escola encobria essa postura -, mas de entender como se constrói uma intersetorialidade com a educação que não coloque a saúde, essa saúde que diagnostica problema e prescreve solução, como autora da verdade final sobre uma prática ou um sujeito e, assim, construir ações efetivas de equidade na rede. O procedimento se tornava objetivo da escrita/pesquisa.

A partir desse procedimento, práticas se inventavam na relação: novos encontros foram desenhados entre as profissionais do Caps e as das escolas. Escolas no plural: saíamos da disputa binária e constituíamos um grupo de encontros ${ }^{27}$ que se punha a pensar soluções, desabafar, errar, esquecer nossos objetivos primeiros, retomar e, principalmente, compactuar corresponsabilizações e coordenar práticas de cuidado com nossas crianças e nossos jovens em comum. A equipe do Caps era convocada a repensar uma clínica para o chão em que pisava. Clínica-política. Que exigia corpo e esforço para construção. Esses encontros eram escritos e reescritos com o esforço de chegar às dimensões coletivas que ali operavam, dando contorno à primeira-pessoa que escreve, localizando-a. A reescrita apontava novas inflexões e derivas que acessavam o plano comum em que as coisas se materializam de uma certa maneira. A escrita e a prática buscavam povoar os gradientes em volta dos binarismos, tais como: pesquisa ou ação, relatório com diagnóstico ou sem diagnóstico, problema da escola ou do Caps... pois os problemas das políticas públicas transversalizam esses binarismos (Romagnoli, 2017).

Era difícil, no entanto, selecionar as cenas, organizar o que vinha delas e cortar. Parecia desonestidade e desrespeito selecionar pedaços que interessavam.

27 Com inspiração em Bastos (2006). 
Só depois compreendi melhor: o corte faz com que a mensagem seja mais bem lida. Em A guerra não tem rosto de mulher, Svetlana Aleksiévitch (2017) não conta as histórias de cada mulher até o fim, uma por uma. Ela as separa por momentos. Os vários pedacinhos de como cada mulher entrou para a guerra juntam mosaicos sobre esse fenômeno. Conta uma história gigante. A maneira de contar importa. Outro exemplo: no site Carcerópolis, ${ }^{28}$ os dados gerais sobre presos no Brasil apontam: mais de 726 mil pessoas estão encarceradas no Brasil. A frase é seguida de "é como se todos os moradores do Amapá estivessem atrás das grades". A sequência dessas duas frases marca a intensidade dessas vidas sem precisar dos detalhes de como foram parar ali. A dimensão coletiva da escrita não está apenas na escolha de palavras, mas na escolha da apresentação, das cenas e na forma de dialogar com o coletivo sobre aquilo que se pensou e se pesquisou.

A palavra é a brincadeira do adulto, ouvi Antônio Nóbrega, um artista brasileiro, dizer uma vez. E foi em um curso de fazer brinquedos educativos que comecei a entender a importância de uma escrita que de fato seja endereçada ao coletivo também em seu formato. Brinquedos e escrita se fazem úteis no mundo na interação com o outro. E assim também são suas criações. Acontece que inventar brinquedos ou brincadeiras exige fazer protótipos. Exige colocar a brincadeira no mundo. A ideia na nossa cabeça não considera gravidade, não considera as partes finas que podem quebrar, as leis da física, a experiência que é lidar com o brinquedo, o que pode ser entediante, se difícil ou fácil demais. Aquilo que se endereça à interação necessita ser colocado a interagir para que saibamos como de fato funciona. Nessa aula de criar brinquedos, havia quem começasse a pensar o brinquedo com uma base amorfa, sobre a qual se penduricalhavam ideias até que uma forma se tomasse. E havia quem fizesse um planejamento primeiro, colocasse a ideia em materialidade para então ajustar o objeto a partir do que a interação entregava de problemas. Todos os resultados eram interessantes e pediam mais de uma versão. E para além: todos requisitavam que se pensasse sempre em quem os usaria.

É que não apenas palavra e brinquedo se fazem úteis no mundo quando postos em interação, eles também criam mundos e sentidos (Bondía, 2002). As palavras com as quais descrevo o objetivo de um encontro ou de uma prática de trabalho criam as premissas da necessidade dessa prática. A palavra do adulto pode capturar a criança em uma explicação opaca sobre o que lhe passa - "delinquentes", "revoltada", "com desvio de conduta" - ou pode, por outro lado,

28 O site Carcerópolis reúne dados e pesquisas sobre a estrutura e a população do sistema prisional. Pode ser acessado em https://carceropolis.org.br/. 
informar os desencontros e as insuficiências que causam os pedidos de ajuda, assim como os suportes para a cooperação no encontro com os Matheus. O encontro de muitos setores, a intersetorialidade, não serve a priori à equidade se não leva em consideração as necessidades da população a que se dedica, uma vez que podem apenas ser muitos setores juntos, aprisionando simbolicamente uma população em sua insuficiência.

Por exemplo, se diferentes áreas sociais nomeiam e generalizam os jovens entre 18 e 24 anos que não têm estudo ou trabalho no Brasil - e que chegavam a 27\% em 2019 (Silva \& Vaz, 2020) - apenas como "nem-nem", 29 as ações dessas áreas podem incorrer no risco de atribuir o estar sem trabalho e sem estudo como responsabilidade apenas dos jovens. Nomeá-los e compreendê-los integralmente como "nem-nem", responsáveis únicos por essa condição, oculta fatores de desigualdade social, de raça, gênero e região que operam nesses números, dificultando o desenho de políticas coordenadas e focalizadas.

Tanto os brinquedos como as frases podem convidar ao movimento, se moldados para celebrar um encontro. A proposta de focarmos a linguagem nas diferenças, e não no diferente, e de falarmos de diferenças funcionais em vez de deficiência (Angelucci, 2014) é eixo central aqui. O não encapsular alguém em uma palavra e, pelo contrário, apontar a diferença entre esse alguém e um outro convida à ação de um encontro. No Caps, algumas professoras e diretoras daquele território concluíram que um relatório que fala dos suportes necessários para uma criança ou adolescente pode ajudar no apoio organizacional de maneira mais precisa que um relatório dedicado ao diagnóstico. Esses suportes necessários não eram concluídos apenas a partir do atendimento no Caps, eram conjeturados nas trocas com a escola. Relatórios feitos em encontros-movimentos intersetoriais e para o movimento de composição com as diferenças. Fenômeno nem sempre possível no dia a dia de um serviço, mas que a pesquisa animava a operar. Pesquisa que fez com que a reescrita se tornasse procedimento e que o cuidado fosse redobrado em relação aos vieses e julgamentos subjetivos primeiros - uma prática de escrita -, esperançando alcançar a dimensão coletiva e considerar sua interação estratégica com o mundo para que possa, de fato, servir de diálogo com ele - uma escrita como prática.

${ }_{29}$ A expressão “nem-nem” se refere a "nem trabalham, nem estudam”. 


\section{REFERÊNCIAS}

Aguiar, K. F. \& Rocha, M. L. (2007). Micropolítica e o exercício da pesquisaintervenção: referenciais e dispositivos em análise. Psicologia, ciência e profissão, 27(4), pp. 648-663.

Aleksiévitch, S. (2017). The Unwomanly Face of War-An oral history of women in World War II. New York: Random House.

Amado, J. (1937). Capitães da areia. Rio de Janeiro: Livraria José Olympio Editora.

Angelucci, C. B. (2014). Medicalização das diferenças funcionais continuísmos nas justificativas de uma educação especial subordinada aos diagnósticos. Nuances: estudos sobre Educação, 25(1), pp. 116-134.

Bastos, M. B. (2006). Transmissão da psicanálise a educadores: quando a circulação da palavra implica um fazer-dizer. In Anais do $6^{\circ}$ Colóquio do LEPSI IP/FE-USP, São Paulo. Disponível em: http://www.proceedings.scielo.br/scielo. php?pid=MSC0000000032006000100005\&script=sci_arttext.

Bondía, J. L. (2002). Notas sobre a experiência e o saber de experiência. Revista brasileira de educação, 19, pp. 20-28. Disponível em: https://doi.org/10.1590/ S1413-24782002000100003.

Conrad, P. (1975). The discovery of hyperkinesis: notes on the medicalization of deviant behavior. Social Problems, 23(1), pp. 12-21.

Machado, A. M. (2016). Analisar uma cena é construí-la. In São Paulo (SP). Secretaria municipal de educação. Núcleo de Apoio e Acompanhamento para Aprendizagem. Caderno de debates do NAAPA: questões do cotidiano escolar (v. 2). São Paulo: SME/COPED. Disponível em: http://portal.sme.prefeitura. sp.gov.br/Portals/1/Files/30293.pdf.

Moysés, M. A. A. \& Collares, C. A. L. (2013). Medicalização: o obscurantismo reinventado. C. A. L. Collares, M. A. A. Moysés \& M. C. F. Ribeiro (Orgs.). Novas capturas, antigos diagnósticos na era dos transtornos. Campinas, SP: Mercado de Letras.

Romagnoli, R. C. (2017). Transversalizando as políticas públicas: quando a intersetorialidade se torna rizomática. Psicologia em Estudo, 22(3), pp. 421-432. Disponível em: https://doi.org/10.4025/psicolestud.v22i3.35843.

Saviani, D. (2012). Escola e democracia (42. ed.). Campinas: Autores Associados. 
Silva, E. R. A. \& Vaz, F. M. (2020). Os jovens que não trabalham e não estudam no contexto da pandemia da Covid-19 no Brasil. In Instituto de Pesquisa Econômica Aplicada. Mercado de Trabalho: Conjuntura e Análise (n. 70). Brasília: IPEA; Ministério do Trabalho. Disponível em: https://www.ipea.gov.br/portal/images/ stories/PDFs/mercadodetrabalho/201104_bmt_70_dossie_a2.pdf. 
